\title{
Topical vancomycine and bacterial culture from intervertebral herniated disc prevent postoperative osteodiscitis
}

\author{
Danil Adam ${ }^{1}$, Toma Papacocea ${ }^{1}$, Ioana Hornea ${ }^{2}$, \\ Cristiana Moisescu ${ }^{2}$ \\ ${ }^{1}$ Carol Davila University of Medicine and Pharmacy, Bucharest \\ 2“Saint Pantelimon" Emergency Hospital, Bucharest
}

\begin{abstract}
Osteodiscitis represents a serious complication of lumbar disc herniation operations. The treatment of osteodiscitis is controversial and expensive to society. It extends over a period of several months from diagnosis. Reducing postoperative osteodiscitis by using simple measures may limit patient's suffering and reduce costs. The purpose of this study is to evaluate the early diagnosis of bacterial infections of the intervertebral disc by isolating germs located in the herniated disc fragment and topical Vancomycine powder application, along with the conventional anti-infective therapy. Medical files of patients who were operated on for lumbar disc herniations during 01.01.2013 - 30.06.2014 were reviewed. The diagnosis of lumbar disc herniation was established based on the clinical evaluation, confirmed by MRI results. The surgical intervention was performed by mini-open approach: fenestration and foraminotomy completed with removal of the herniated disc fragment and disc remnants from the intervertebral space. A group of 162 patients (group A) received conventional therapy for prevention of post-operative infections with 2 doses of cephalosporin. In the second group of 137 patients (group B), after the removal of the herniated disc fragments, $1 \mathrm{~g}$ of Vancomycine powder was topically applied and the disc fragments were bacteriologically analyzed. They received the conventional treatment of preventing post-operative infections with cephalosprin - 2 doses. The two groups of patients were similar in terms of demographic characteristics: age, sex, operative level. Out of the 162 patients of group A, one patient developed postoperative osteodiscitis and was treated for 3 months with antibiotics. Regarding patients in group B, in four cases Staphylococcus was isolated from the disc fragments. Postoperative treatment for these patients with prolonged antibiotic therapy over the standard period avoided the developement of the clinical picture of osteodiscitis. Postoperative osteodiscitis requires prolonged antibiotherapy. By using simple measures, like topical Vancomycine powder application and early isolation of germs from the herniated intervertebral disc, followed by the immediate establishment of appropriate antibiotic treatment, this serious complication is avoided.
\end{abstract} Key words: herniated disc, osteodiscitis, Vancomycine, microbiological examination. 


\section{Introduction}

Among nosocomial infections, those that occur at the place of the surgical intervention are the most common. They have not only a socio-economic impact but affect both the patient - whose quality of life is reduced, and the treating surgeon - whose professional prestige suffers.

Postoperative osteodiscitis has an incidence of 0.2 to $3.0 \%(1,2)$ among interventions for lumbar disc herniations, and $0.2-0.4 \%$ in recent series. $(3,4)$

The treatment for osteodiscitis, conservative or surgical debridement, is in both cases long-termed and expensive.

Prevention of postoperative infections is accomplished by using simple aseptic measures and short-term prophylactic antibiotics.

Topical application of Vancomycine powder proved to be effective in reducing post-operative infection rate. (5)

Microbiological disc examination and culture and sensitivity together with lab tests (count of white blood cells, erythrocyte sedimentation rate and C-reactive protein) help in early diagnosis and treatment of infection especially regarding patients with risk factors.

The aim of the study is to evaluate the role of topical Vancomycine powder application and microbiological examination of the disc fragments comparing a group of patients operated on for lumbar disc herniations where these measures were applied, with another group of patients operated on for lumbar disc herniations where the conventional prophylactic antibiotherapy was applied.

\section{Material and methods}

A series of 299 patients were operated on for lumbar disc herniations during a period of 18 months (January 2013 - June 2014), through a mini-open approach previously described. (6)

Briefly, we performed a unilateral interlamar approach with fenestration and foraminotomy followed by removal of the herniated fragment and curettage of the disc space.

Regarding group A consisting of 162 patients, prevention of postoperative infection was made using the conventional classical methods: intra and postoperative strict asepsis associated with prophylactic antibiotherapy (two doses of cephalosporin).

Regarding group B consisting of 137 patients, in addition to the means of prevention postoperative infection applied to group A, at the surgical site it was applied $1 \mathrm{~g}$ of Vancomycine powder before wound closure. In this group of patients, a microbiological examination of the resected disc fragments was made. For patients with positive microbiological results, specific antibiotherapy was continued, based on the sensitivity of isolated pathogens.

Several risk factors have been identified by several studies in the literature related to postoperative infections. (7)

Among them, the most common risk factors are obesity, diabetes, smoking, existence of previous infection before surgery on the skin or urinary infections. 
DOI: 10.2478/romneu-2014-0057

\section{Results}

The two groups of patients were similar in terms of demographic characteristics. (Table I)

Lumbar disc herniation was more common among men. The median age was 53.3 years in group A and 45.8 years in group B. Patients at the peak of their professional activity represented $71 \%$ in group A and $74.4 \%$ in group B.

The most common sites of lumbar disc herniations have been at L4-L5 and L5-S1 in both groups.

One patient from group A developed postoperative osteodiscitis. Symptoms appeared 18 days after surgery with local pain, low grade fever, elevated ESR and CRP.
MRI examination showed a hyperintense image in the L4-L5 disc space. The patient required surgical debridement, Staphylococcus Aureus was isolated and antibiotic treatment with Cefazoline followed for 3 months. During this period of time the patient wore a Boston brace.

In 4 patients from group B, Staphylococcus was isolated from the intervertebral disc fragments (Table II). Out of these, 1 patient presented staphylococcal skin infection, another one type II diabetes and the third one obesity, as risk factors. Patient 2 had underwent surgery for lumbar disc herniation at the same level 3 months earlier.

TABLE I

Patients' characteristics

\begin{tabular}{|l|l|l|}
\hline Characteristics & Group A - no., $\%$ & Group B - no., $\%$ \\
\hline Number of cases & $162(54.1 \%)$ & $137(45.8 \%)$ \\
\hline Gender & & \\
male & $93(57,4 \%)$ & $86(62,7 \%)$ \\
\hline Risk factors & & \\
obesity & $17(5.6 \%)$ & $13(4.3 \%)$ \\
diabetes & $26(8.6 \%)$ & $17(5.6 \%)$ \\
smoking & $20(6.6 \%)$ & $29(9.6 \%)$ \\
\hline Age (years) & & \\
- mean age & 53,3 & 45,8 \\
- 20-29 & $7(2.3 \%)$ & $5(1.6 \%)$ \\
- 30-39 & $36(12.04 \%)$ & $27(9.03 \%)$ \\
- 40-49 & $27(9.03 \%)$ & $41(13.7 \%)$ \\
- 50-59 & $44(14.7 \%)$ & $29(9.6 \%)$ \\
- 60-69 & $24(8.02 \%)$ & $26(8.6 \%)$ \\
- 70-79 & $23(7.6 \%)$ & $9(3.01 \%)$ \\
\hline Level & & \\
- L2-L3 & $5(1.6 \%)$ & - \\
- L3-L4 & $10(3.3 \%)$ & $3(1.003 \%)$ \\
- L4-L5 & $70(23.4 \%)$ & $71(23.7 \%)$ \\
- L5-S1 & $77(25.7 \%)$ & $63(21.07 \%)$ \\
\hline Osteodiscitis & $1(0.61 \%)$ & - \\
\hline Positive disc cultures & - & $4(1.33 \%)$ \\
\hline
\end{tabular}


TABLE II

Characteristics of patients with pathogens isolated from the intervertebral disc

\begin{tabular}{|l|l|l|l|l|l|l|}
\hline No. & Gender & Age & Level & Risk factors & Pathogen & Treatment \\
\hline 1. & M & 58 & L4-L5 & $\begin{array}{l}\text { staphylococcal } \\
\text { skin }\end{array}$ & $\begin{array}{l}\text { coagulase } \\
\text { positive } \\
\text { staphylococci }\end{array}$ & $\begin{array}{l}\text { Cefort }+ \\
\text { Ciprofloxacin - } \\
\text { week } \\
\text { Ciprofloxacin }+ \\
\text { Biseptol - 2 weeks }\end{array}$ \\
\hline 2. & M & 61 & L3-L4 & $\begin{array}{l}\text { recent surgery } \\
\text { at the same } \\
\text { level }\end{array}$ & $\begin{array}{l}\text { coagulase } \\
\text { positive } \\
\text { staphylococci }\end{array}$ & $\begin{array}{l}\text { Ciprofloxacin - } 10 \\
\text { days }\end{array}$ \\
\hline 3. & F & 42 & L4-L5 & $\begin{array}{l}\text { grade III } \\
\text { obesity } \\
\text { smoker }\end{array}$ & $\begin{array}{l}\text { staphylococcu } \\
\text { s aureus }\end{array}$ & $\begin{array}{l}\text { Ciprofloxacin+ } \\
\text { Biseptol - one } \\
\text { month }\end{array}$ \\
\hline 4. & M & 52 & L5-S1 & $\begin{array}{l}\text { type II } \\
\text { diabetes }\end{array}$ & $\begin{array}{l}\text { staphylococcu } \\
\text { s aureus }\end{array}$ & Tavanic - 3 weeks \\
\hline
\end{tabular}

Immediately after the pathogens were isolated and their sensitivity to antibiotics was tested, appropriate antibiotherapy for a period of 10 to 30 days was initiated.

No patient had clinical symptoms specific to osteodiscitis. One patient presented changes in the erythrocyte sedimentation rate $(37 \mathrm{~mm} / \mathrm{h})$ and C-reactive protein $(10.6$ $\mathrm{ng} / \mathrm{mL}$ ) which normalized after a month of treatment.

Patient no. 3, who presented with varicose veins in the legs, developed after surgery a superficial thrombophlebitis in the left leg. In this patient with grade III obesity, partial wound dehiscence occurred which required resuture at the inferior pole.

All patients were discharged after 7 days. Postoperative course was uneventful after discharge.

At the 1 month postoperative follow-up, no patient showed any specific symptoms of osteodiscitis, laboratory tests were normal and the symptoms of a herniated disc had an improvement between $80 \%$ and $100 \%$ after patients' evaluation.

\section{Discussion}

Infection of intervertebral disc creates a serious suffering for patients operated for lumbar disc herniations, prolonging antibiotic treatment for several months, whether it is treated conservativly or surgically.

Pathogen inoculation can be done directly during surgery from an infection of the skin, or hematogenously from an infectious outbreak in the body, most often from a neglected genitourinary infection or an infection of the intestinal tract. In over half of the cases, the source of infection remains unidentified. (8)

The most common pathogen isolated in cases of osteodiscitis is Staphylococcus. (9)

The clinical picture of osteodiscitis appears 
on average after 2-3 weeks with back pain and spinal stiffness accompanied by low-grade fever or fever and sweating.

The biological markers of osteodiscitis, erythrocyte sedimentation rate and C-reactive protein values are above normal and can serve both as tests to monitor disease progression and treatment effectiveness. Leukocytosis is inconsistent. (8)

Early detection of changes that occur at the disc space and adjacent end-plates is done by modern imaging means, MRI.

Isolation of the pathogens is done by puncture biopsy or open biopsy, in which case inflamed tissue debridement is also performed.

Antibacterial treatment consists of antibiotics intravenously administrated for 23 weeks and, after the improvement of the erythrocyte sedimentation rate and C-reactive protein, orally administrated for 6 weeks to 3 months.

In the prevention of postoperative osteodiscitis strict aseptic measures have an important role.

As for surgery for lumbar disc herniation is rarely an emergency, preoperative diagnosis and appropriate treatment of possible genitourinary infections or infections in other sites is important for reducing the incidence of osteodiscitis. The first step in this regard is a proper history and general and local clinical examination.

In recent years, it was shown that topical Vancomycine powder application before suturing the lumbar aponeurosis is effective in reducing postoperative infections (5).
Since 2012 we have applied this policy to reduce postoperative infections in spine interventions.

Since 2013, regarding surgical interventions for lumbar disc herniations, we studied the presence of microbial pathogens in the herniated intervertebral disc.

In the present study we analyzed the outcome of patients who underwent surgery for lumbar disc herniations and the incidence of postoperative osteodiscitis comparing two groups of patients. One group received 2 doses of cephalosporins to prevent postoperative infection. In the second group, we microbiologically analyzed the presence of bacteria in the herniated disc fragments.

In the cases where the microbiological examination confirmed the presence of microbial pathogens, germ sensitivity appropriate antibiotherapy was continued from 10 to 30 days.

From the first group of patients, one patient developed osteodiscitis. From the second group, in 4 cases there was revealed the presence of Staphylococcus in the disc fragments. Antibiotherapy immediately instituted prevented the development of postoperative osteodiscitis and the modification of the biological markers of inflammation in all cases but one. Regarding this patient, erythrocyte sedimentation rate and C-reactive protein normalized after one month.

Comparing patients from the two groups regarding the developement of postoperative osteodiscitis, it seems that patients from group $B$ were more likely to develop osteodiscitis than patients from group $\mathrm{A}$, despite the topical 
Vancomycine powder application in addition to the conventional antibiotic treatment and early detection of germs in disc fragments, followed by adequate antibiotic administration.

We do not know if, had these patients not have been treated with antibiotics, clinical and biological changes of discitis would have developed.

In reality, only one patient presented changes of the biological inflammatory tests.

Further studies focused on the evolution of patients with positive microbiological tests using a comparison between the treated and the non-treated ones, which seems highly unethical.

There are several limitations regarding our study. Firstly, this is a retrospective study which implies the fact that a full characterization of isolated germs is missing. Secondly, we suspect that the microbiological tests were not immediately worked which possibly permitted bacterial contamination of the sample. Our initial results have yet to be confirmed by further prospective studies.

\section{Conclusions}

Postoperative osteodiscitis is a rare but serious complication of lumbar disc herniation surgery. Its treatment, conservative or surgical, is both resource and time consuming.

For the prevention of postoperative osteodiscitis, in addition to the conventional measures, topical Vancomycine powder application, in the wound, and the search for the presence of microbial pathogens in the disc fragments followed by appropriate antibiotherapy, are proving effective.

\section{References}

1. Brussatis F: Osteomyelitis nach Operation lumbaler Disckuchernien. Acta Neurochir (Wien) 2: 209-230, 1953.

2. Pilgaard S: Discitis following removal of lumbar intervertebral disc. JBoneJoinSurg (Am) 511: 713-716, 1969.

3. Boden SD, Davis Do, Dina TA, et al: Postoperative Diskitis: Distinguishing Early MRImaging Findings from Normal Postoperative Disk Space Changes. Radiology 184: 765-771, 1992.

4. Roth SA, Neff U, Schneider O, Richter HP: Neurosurgical management of thoracic and lumbar vertebral osteomyelitis and discitis in adults. Neurosurgery 1996: 38: 926-933.

5. RW Molinari, OA Khera, WJ Molinari III: Prophylactic intraoperative powdered vancomycin and postoperative deep spinal wound infection: 1,512 consecutive surgical cases over a 6-year period. European Spine Journal, 2012 - Springer

6. Adam D, Nica D: Hernia de disc lombară. Neurologia medico-chirurgicală 2000, 1: 8-13.

7. Albert F. Pull ter Gunne, David B. Cohen.: Incidence, Prevalence, and Analysis of Risk Factors for Surgical Site Infection Following Adult Spinal Surgery. Spine 34:13, 1422-1428.

8. Jensen AG, Espersen F; Skinhj P, et al: Bacteremic staphylococcus aureus spondylitis. Arch Intern Med, 158: 509-517, 1998.

9. Dufour V, Feydy A, Rillardon L, et a: Comparative study of postoperative andspontaneous pyogenic spondylodiscitis. Lemin Arthritis Rheum, 34: 766-771, 2005. 